\title{
Control Radiation Pattern for Half Width Microstrip Leaky Wave Antenna by Using PIN Diodes
}

\author{
Mowafak K. Mohsen ${ }^{1}$, M.S.M. Isa ${ }^{2}$, Z.Zakaria ${ }^{3}$, A.A.M. Isa ${ }^{4}$, M. K. Abdulhameed ${ }^{5}$, \\ Mothana L. Attiah ${ }^{6}$ \\ ${ }^{1,2,3,4,5,6}$ CeTRI, Faculty of Electronic and Computer Engineering, Universiti Teknikal Malaysia Melaka, Malaysia \\ ${ }^{1,5}$ Ministry of Higher Education and Scientific Research, Iraq
}

\section{Article Info}

Article history:

Received Mar 18, 2018

Revised Jul 18, 2018

Accepted Aug 9, 2018

\section{Keyword:}

Control cell

Gap capacitor

HW-MLWA

Leaky wave

LWA

Radiation pattern

\begin{abstract}
In this paper, a novel design for single-layer half width microstrip leakywave antenna (HW-MLWA) is demonstrated. This model can be digitally control its radiation pattern at operation frequency and uses only two values of the bias voltage, with better impedance matching and insignificant gain variation. The scanning and controlling the radiation pattern of leaky-wave antennas (LWA) in steps at an operation frequency, by using switches PIN diodes, is investigated and a novel HW-MLWA is introduced. A control cell reconfigurable, that can be switched between two states, is the basic element of the antenna. The periodic LWA is molded by identical control cells where as a control radiation pattern is developed by combining numerous reconfigurable control cells. A gap capacitor is independently connected or disconnected in every unit cell by using a PIN diode switch to achieve fixedfrequency control radiation pattern scanning. The profile reactance at the free edge of (HW-MLWA) and thus the main lobe direction is altered by changing the states of the control cell. The antenna presented in this paper, can scan main beam between $18 \mathrm{o}$ to $44 \mathrm{o}$ at fixed frequency of $4.2 \mathrm{GHz}$ with measured peak gain of $12.29 \mathrm{dBi}$.
\end{abstract}

Copyright (C) 2018 Institute of Advanced Engineering and Science. All rights reserved.

\section{Corresponding Author:}

Mowafak K. Mohsen,

CeTRI, Faculty of Electronic and Computer Engineering,

Universiti Teknikal Malaysia Melaka,

Hang Tuah Jaya, 76100 Durian Tunggal, Melaka, Malaysia.

Email: saari@utem.edu.my,mowafak.k.m@gmail.com

\section{INTRODUCTION}

The control radiation pattern abilities from planar low-profile structures of (HW-MLWAs) make them attractive choice for designers. This inherent beam scanning capability of leaky-wave antennas (LWAs) makes them a very suitable choice for numerous applications such as automotive radar and multipoint communication [1],[2]. Microstrip based LWAs were first projected in 1978 with methods to excite a higher order mode [3]. Discussed and explained these antennas in detail at later stages by explaining the radiation characteristics of higher order microstrip modes[4],[5]. In past, many types of leaky wave antennas have been designed for control radiation pattern by varying the operating frequency [6]-[14]. The towards of the main lobe of a LWA is given by [15]

$$
\theta(f)=\sin ^{-1}\left[\frac{\beta(f)}{k_{o}(f)}\right]
$$

where $\beta$ is defined as the phase constant, $k_{o}$ is the wave number of free-space, and $\theta(f)$ is the boresight angle, $k_{0}$ is fixed in fixed-frequency beam steering. So, effective phase constant $(\beta)$ must be altered by some other method without significantly varying the frequency. The main lobe direction can be changed by, for instance, 
varying the reactance profile of microstrip line which in turn alter the effective $\beta$ of the line [16].

Most of the communication systems are operated in predefined frequency bands. demonstrated another method in which changing the positions of feed along one edge of the full width multi-terminal microstrip leaky wave antenna, 20 lumped capacitors were used in [16] for the demonstration of control main beam at fixed frequency by loading such capacitors at the one edge of HW-MLWA. The frequency bands for such communications are often narrow, so it is highly desirable to scan the beam at a certain fixed frequency [17], [18]. There is a lot of research in this area and many models have been introduced for this. One such method is changing the values of lumped capacitors when they are loaded to the leaky slots of periodical design of LWA [19], [20]. Yet in another research [21], electronic beam scanning was attained at fixed frequency by changing the varactors voltage in a 1-D Fabry-Perot LWA. The researchers in [22] connected 35 limped capacitors to the microstrip free edge for the predicted radiation patterns for a reconfigurable HW-MLWA. The full control for radiation pattern at certain frequency in [23],[24] by varying the biasing voltage of varactor loaded composite right-left/handed (CRLH) MLWA. It was found by [25] that if MLWA is loaded with multiple stubs on both edges of microstrip, it is possible to get beam scanning at fixed frequency provided spacing between adjacent stubs is varied. The researchers considered open-circuit and short-circuit stubs for their design.

In this paper, a reconfigurable half-width MLWA (HW-MLWA) is presented. One side of the HWMLWA is loaded by control cells are contain from two triangular periodic patches that can be selective connected to ground using switches PIN diodes. Changing the periodic loading on the microstrip line change the effective $\beta$ of the radiation line. Therefore, radiation pattern can be steered by controlling the states (ON and OFF) of the PIN diodes.

\section{ANTENNA CONFIGURATION}

The structure proposed is a modified HW-MLWA with periodic control cell as shown in Figure 1a. This HW-MLWA is designed on Rogers RT5880 substrate with $\varepsilon r=2.2$, and $\tan \delta=0.0009$. Length $(L)$, width $(W)$, and height $(h)$ of the substrate is $231 \mathrm{~mm}\left(3.234 \lambda_{0}\right), 47 \mathrm{~mm}\left(0.658 \lambda_{0}\right)$, and $1,575 \mathrm{~mm}$, respectively, where $\lambda_{o}$ denotes the free-space wavelength that is calculated at $4.2 \mathrm{GHz}$. Length and width of the ground plane has the same respective dimensions of the substrate. The length $\left(l_{p}\right)$ and the width $\left(W_{p}\right)$ of microstrip line is $222 \mathrm{~mm}\left(3.108 \lambda_{o}\right)$ and $12 \mathrm{~mm}\left(0.168 \lambda_{o}\right)$, respectively.

The proposed HW-MLWA is fed from one end of the radiation element using a standard SMA feed and the other end is terminated with a $50 \Omega$ matched load (lumped element) to avoid reflection and to achieve good impedance matching as demonstrated in Figure 1(b). and 1(c). Dimensions of the feed line are optimized according to some parametric studies. The optimum parameter values for the length $\left(l_{f}\right)$ and width $\left(w_{f}\right)$ of the feed end are $4.5 \mathrm{~mm}$ and $4 \mathrm{~mm}$, respectively. One edge of microstrip line is connected to the ground using a vias array, which is placed along the edge of microstrip line. Major purpose of the vias array is to avoid the propagation of the fundamental transversal electromagnetic (TEM) wave and to support the propagating of first higher order mode through the structure [26], [27]. The proposed antenna to shorten the edge are used 109 vias. The design configurations of these structures have been presented in. The metallized diameter $(d)$ and distance $(S)$ between the two adjacent vias can be calculated using the following equations, that set the design rules [28],[29]

$$
d>0.2 \lambda_{o}, \frac{d}{S} \leq 0.5
$$

The distance $(S)$ between the two vias is $1.5 \mathrm{~mm}$, and the value of the diameter $(d)$ of each via is $0.8 \mathrm{~mm}$. The appropriate gap $(m)$ between the feed and the first via and gap $(n)$ between the first control cell and feed are $4.9 \mathrm{~mm}$ and $30.3 \mathrm{~mm}$, respectively. As shown in Figure 1(c), these gaps are required to force the wave toward the microstrip edges and improve matching impedance [30].

\section{CONTROL CELL CONFIGURATION}

The concept of cascading multiple type of unit cells to create a larger cell has been previously studied by [31][32] for nonreconfigurable structures. Major drawback in that approach is that this design system is nonreconfigurable, which means large cells cannot be operated for other configurations after fabrication. In this research, the idea of a reconfigurable control cell is presented, which consists of small reconfigurable unit cells. The design allows to dynamically change the characteristics and size of the large-cell.

The free edge of microstrip line contains (7) equally spaced control cells with a space separation 
between cells $\left(C_{3}\right)$ of $30 \mathrm{~mm}$. Each cell contains two triangular patches and the dimension of each triangle is $\left(C_{1}\right)(10 \mathrm{~mm})$ and $C_{2}(8.12 \mathrm{~mm})$. A set of control cell patches, was putted very closer to the microstrip line's free edge, leaving a narrow $0.3 \mathrm{~mm}$ gap $\left(g_{1}\right)$ between them, and the gap between the triangles in control cell $\left(g_{2}\right)$ is $0.2 \mathrm{~mm}$ as shown in Figure 1(b). Each control cell consists of two triangular patches, two PIN diodes are working as binary switch and two vias that goes through the substrate than connected to the ground level. The PIN diode is connected with the triangular patch plan through its $p$-terminal whereas the $n$-terminal is connected to a via as shown in Figure 1(c).

The $p$-terminal of every diode is attached independently to the positive terminal of DC power supply using externally controlled switches. The ground plane is connected with the other terminal (-ve) of the DC supply. When a diode is in ON state, i.e. forward biased, the patch is connected to the ground and when the diode is in OFF state, i.e. reverse biased, the patch is isolated from the ground. Having a separate connection to the $p$-terminal provides an individual control of the states of each diode. In this way, the patches can be controlled individually.

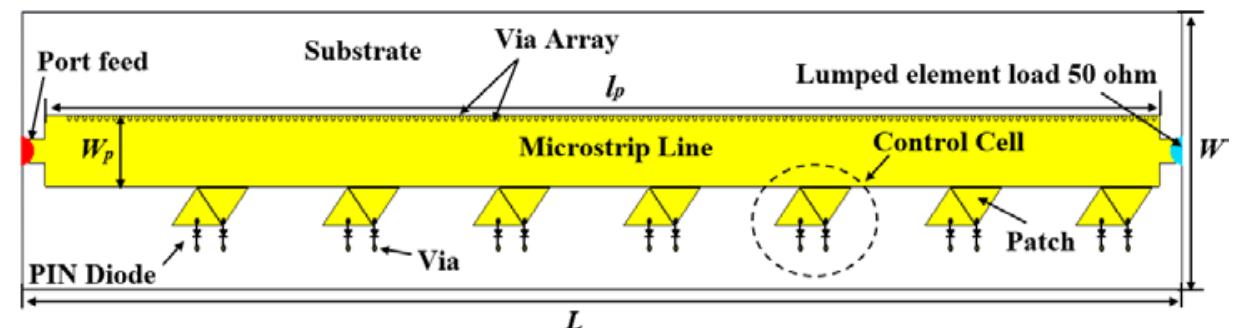

(a)

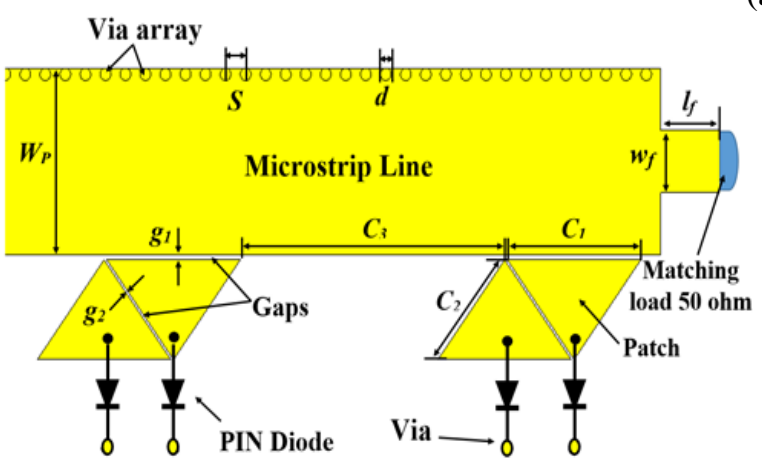

(b)

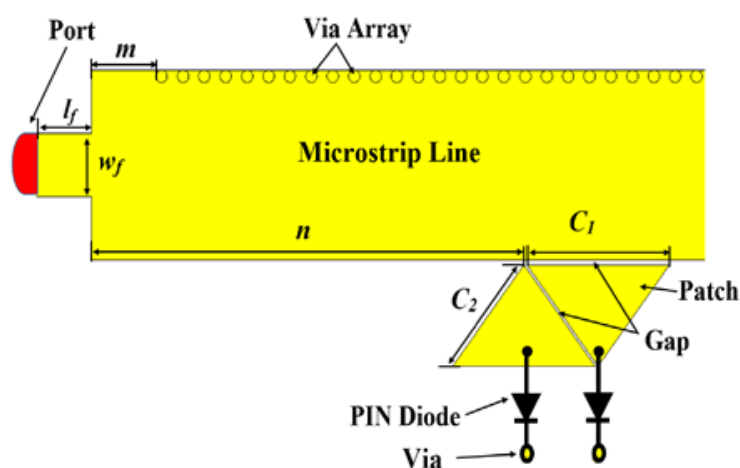

(c)

Figure 1. Reconfigurable periodic HW-MLWAs, (a) top view, (b) matching load with control cell (c) port and feed line

\section{RESULTS \& DISCUSSION}

The PIN diodes were simulated as ideal switches in this design. In the (ON) state, the diode acts as a short circuit and in (OFF) state the diode acts as an open circuit. Hereafter, ON state will be denoted as " 1 " and OFF state as "0". Since each PIN diode can be individually controlled, wide variety of switch configurations are possible. The radiation of the HW-MLWA was tested for 7 selected states of switch configurations which are summarized in Table 1. The radiation patterns at $4.2 \mathrm{GHz}$ for these switch configurations are demonstrated in Figure 2 it is clear from the figure that the main beam can be steered from $18^{\circ}$ to $44^{\circ}$ in discrete steps by switching between the selected switch configurations.

The state of each PIN diode changes the reactance between the corresponding triangular patch and ground. Having different switch configurations introduces different reactance profiles along the microstrip line. Each of these reactance profiles provides a distinct phase constant $(\beta)$ for the HW-MLWA at a fixed operating frequency. As a result, the main beam direction $\left(\theta_{m}\right)$ changes with each switch configuration. When MLWAs are designed by this approach and their radiation pattern are analyzed, the major factor considered is the complex propagation constant on the reconfigurable HW-MLWA structure of the microstrip line, which is computed by using $k=\beta-\alpha j$, here $\alpha$ is defined as attenuation constant [33],[34]. There is a specific average value of $\beta$ and $\alpha$ at a given frequency for each control cell state, and in the HW- LWAs, the direction of the main beam which is related to $\beta$ as per Equation (1). Let the number of patches in a control 
cell defines the order of a control cell $(N)$, A multi-state of control cell can be considered as element electromagnetic with $2^{N}$ states.

Table 1. Selected Switch States and Corresponding Main Lobe Directions at 4.2 GHz

\begin{tabular}{ccc}
\hline $\begin{array}{c}\text { State } \\
\text { No. }\end{array}$ & Switch states & $\begin{array}{c}\text { Main lobe } \\
\text { Direction }(\theta m)\end{array}$ \\
\hline 1 & $10-10-10-10-10-10-10$ & $18^{\circ}$ \\
2 & $00-00-10-10-10-10-10$ & $24^{\circ}$ \\
3 & $00-00-10-10-00-00-00$ & $28^{\circ}$ \\
4 & $00-01-01-01-01-01-00$ & $31^{\circ}$ \\
5 & $00-00-00-00-00-00-00$ & $34^{\circ}$ \\
6 & $11-11-11-00-00-00-00$ & $40^{\circ}$ \\
7 & $11-11-11-11-11-11-11$ & $44^{\circ}$ \\
\hline
\end{tabular}

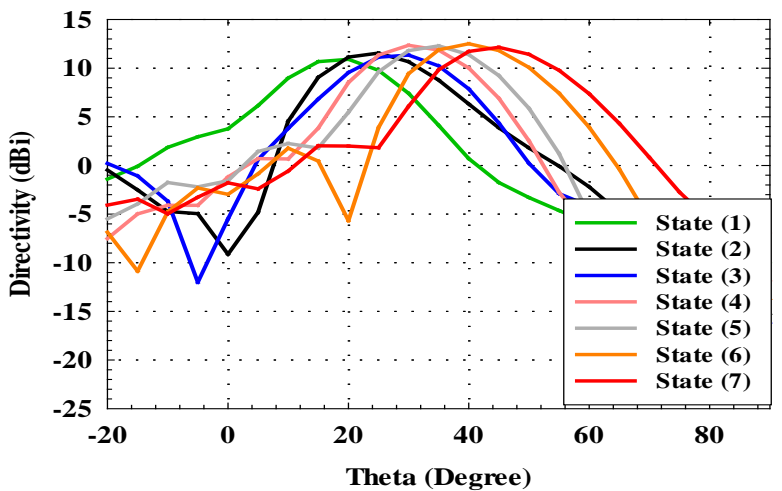

Figure 2. Directivity (dBi) of the proposed HW-MLWA at $4.2 \mathrm{GHz}$ for seven states selected switching configurations

The proposed design has 7 control cells, each cell has two patches, hence there are of total $2^{14}$ (16384) states. For example, In state (1), each cell has two PIN diodes, one patch is in ON and other is in OFF state i.e. the capacitance between the triangular patches and the ground is larger as compared to the state (7). By observing the radiation patterns for state (1) and state (7) it is clear that higher capacitance i.e. a smaller reactance, results in a main beam directed away from endfire and smaller capacitance i.e. larger reactance, results in a beam directed towards endfire. Further, this observation leads us to conclude that turning the PIN diodes ON results in a relatively smaller effective $1 \beta$ compared to the effective $2 \beta$ when all PIN diodes are OFF. The radiation efficiency of this HW-MLWA is shown in Figure 3 for different main beam directions. The radiation efficiency is high for the beams directed closer to 180 and the efficiency decreases when approaching the endfire.

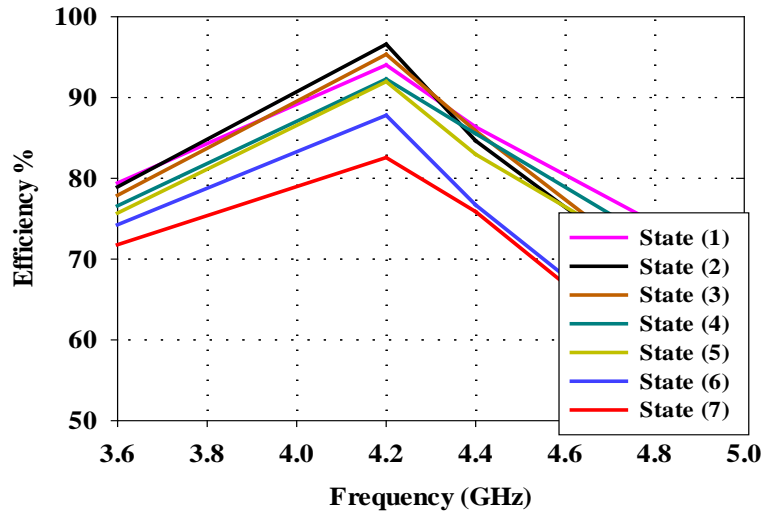

Figure 3. Radiation efficiency of the proposed antenna for 7 states at $4.2 \mathrm{GHz}$ 
The input reflection coefficient magnitudes for the seven main switch configurations are shown from Figure 4 to Figure 10. It can clearly be seen from the figures that the HW-MLWA has a return loss $S_{11}$ for reconfigurable HW-MLWA is greater than $10 \mathrm{~dB}$ at $4.2 \mathrm{GHz}$ for all listed switch configurations. Few control cell states have been excluded that have low gain. This could be, for example due to poor input matching. Although, this research presented the antenna beam steering for $4.2 \mathrm{GHz}$ operation, it is possible to steer the beam at other frequencies as well. We need to select appropriate control cell states for the desired frequency, and due to inherent design of LWAs.

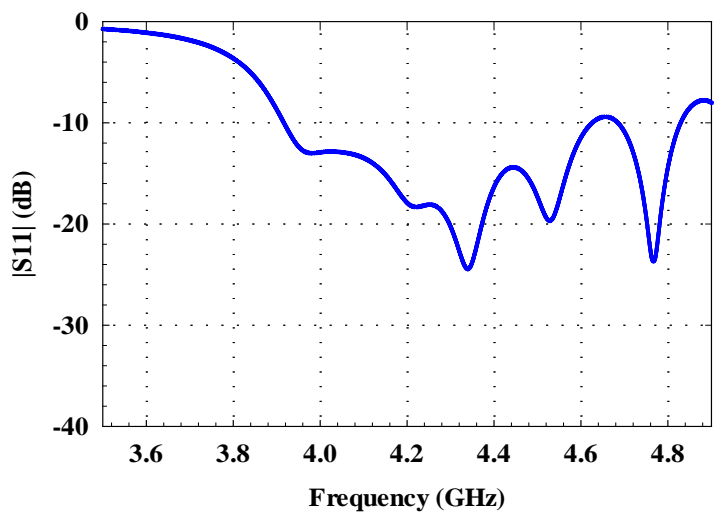

Figure 4. $\left|\mathrm{S}_{11}\right|$ for the state (1) of the proposed antenna

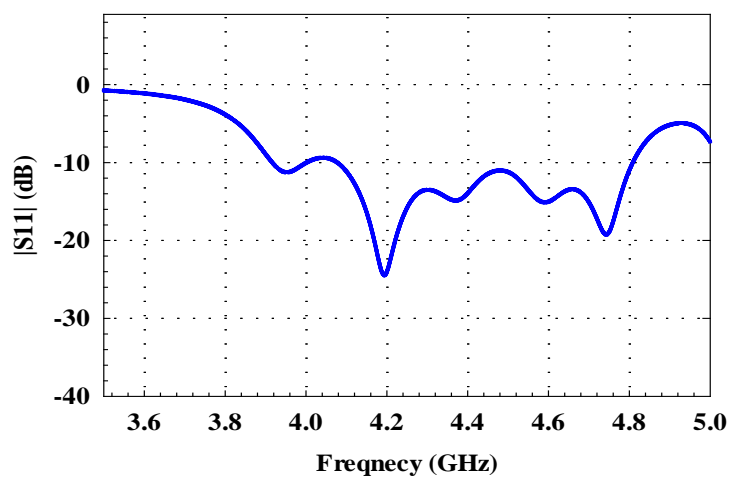

Figure 6. $|\mathrm{S} 11|$ for the state (3) of the proposed antenna

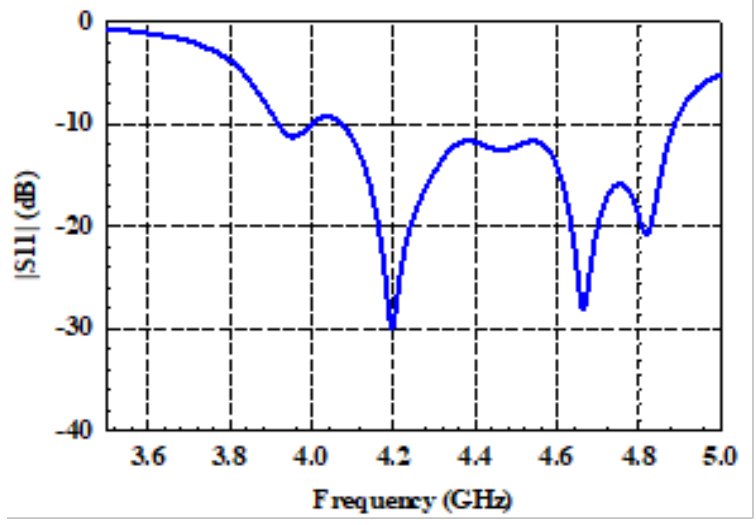

Figure 5. $|\mathrm{S} 11|$ for the state (2) of the proposed antenna

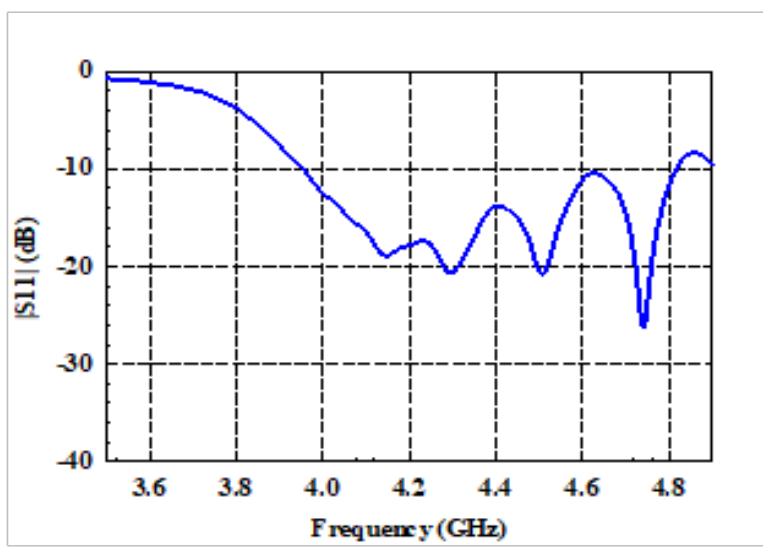

Figure 7. $|\mathrm{S} 11|$ for the state (4) of the proposed antenna

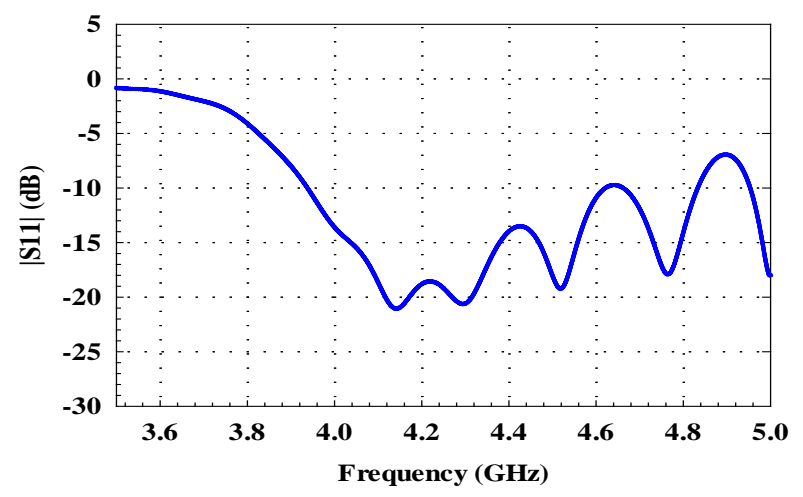

Figure 8. $|\mathrm{S} 11|$ for the state (5) of the proposed antenna 




Figure 9. $|\mathrm{S} 11|$ for the state (6) of the proposed antenna

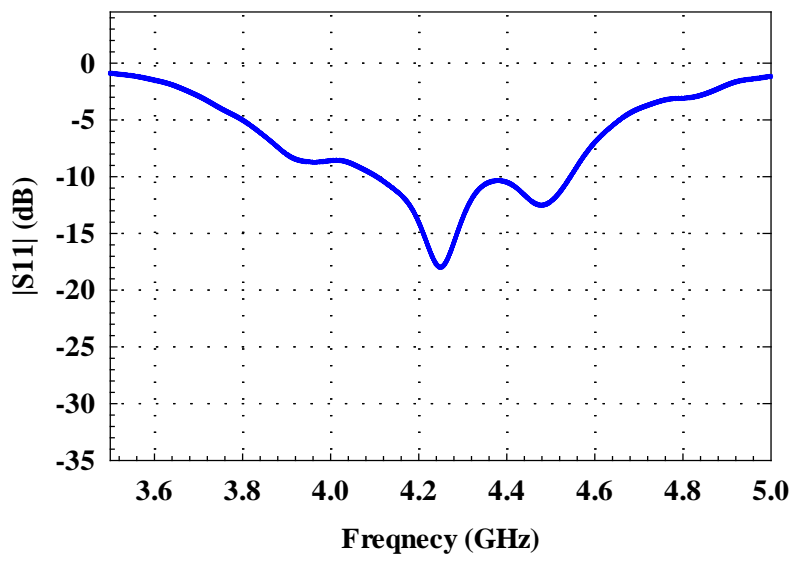

Figure 10. $|\mathrm{S} 11|$ for the state (7) of proposed antenna

\section{CONCLUSION}

The change in the reactance profile in a HW-MLWA changes the effective phase constant $\beta$ at a fixed frequency. This can be used to attain fixed frequency beam scanning in a design where the fundamental TEM mode is suppressed while $\beta$ is varied for the first higher-order mode. Thus, a novel approach is presented to control the main lobe of periodic HW-MLWAs at a fixed frequency by means of only binary values of (either On or OFF) DC bias voltage. We had achieved the controlled radiation pattern without varying the frequency by loading the gap capacitors periodic at the free edge of the reconfigurable HW-MLWA and their ground plan connection was controlled by binary switches. A multi-state control cell method has been originated to analyze reconfigurable periodic structures which is then applied for the design of HW-MLWAs. The approach helped to conduct the design and analysis of a reconfigurable periodic structure in systematic manner. This design provided a wide variety of switch configurations that can control the main beam direction from $18^{\circ}$ to $44^{\circ}$ in discrete steps. The peak value of gain is $12.29 \mathrm{dBi}$ at $4.2 \mathrm{GHz}$.

\section{ACKNOWLEDGEMENTS}

This work was supported by UTeM Zamalah Scheme. The authors would also like to thank the Center for Research and Innovation Management (CRIM), Centre of Excellence, UTeM, UTeM's research grant JURNAL/2018/FKEKK/J00001 and Universiti Teknikal Malaysia Melaka (UTeM) for their encouragement and help in sponsoring this research. 


\section{REFERENCES}

[1] D. K. Karmokar and K. P. Esselle, "Periodic U-Slot-Loaded Dual-Band Half-Width Microstrip Leaky-Wave Antennas for Forward and Backward Beam Scanning,” IEEE Trans. Antennas Propag., vol. 63, no. 12, pp. 53725381, 2015.

[2] M. K. Mohsen et al., “The Fundamental of Leaky Wave Antenna,” vol. 10, no. 1, pp. 119-127, 2018.

[3] W. Menzel, “A new travelling-wave antenna in microstrip,” Arch. Elektron. und Uebertragungstechnik, vol. 33, no. 2, pp. 137--140, 1979.

[4] H. Ermert, U. Erlangen-numberg, and D.- Erlangen, "Guiding and radiation characteristics of planar waveguides," Iet Microwaves, Opt. Acoust., vol. 3, no. 2, pp. 59-62, 1979.

[5] A. A. Oliner, Leakage from higher modes on microstrip line with application to antennas, vol. 22, no. 6. Radio Sci, 1987.

[6] J. Liu, D. R. Jackson, Y. Li, C. Zhang, and Y. Long, "Investigations of SIW leaky-wave antenna for endfireradiation with narrow beam and sidelobe suppression," IEEE Trans. Antennas Propag., vol. 62, no. 9, pp. 44894497, 2014.

[7] Nasimuddin, Z. N. Chen, and X. Qing, "Multilayered composite right/left-handed leaky-wave antenna with consistent gain,” IEEE Trans. Antennas Propag., vol. 60, no. 11, pp. 5056-5062, 2012.

[8] C. Jin and A. Alphones, "Leaky-wave radiation behavior from a double periodic composite right/left-handed substrate integrated waveguide,” IEEE Trans. Antennas Propag., vol. 60, no. 4, pp. 1727-1735, 2012.

[9] G. F. Cheng and C. K. C. Tzuang, "A differentially excited coupled half-width microstrip leaky mode antenna," IEEE Trans. Antennas Propag., vol. 61, no. 12, pp. 5885-5892, 2013.

[10] N. Nguyen-Trong, T. Kaufmann, and C. Fumeaux, "A wideband omnidirectional horizontally polarized travelingwave antenna based on half-mode substrate integrated waveguide,” IEEE Antennas Wirel. Propag. Lett., vol. 12, pp. 682-685, 2013.

[11] A. Pourghorban Saghati, M. M. Mirsalehi, and M. H. Neshati, “A HMSIW circularly polarized leaky-wave antenna with backward, broadside, and forward radiation,” IEEE Antennas Wirel. Propag. Lett., vol. 13, pp. 451-454, 2014.

[12] N. Nasimuddin, Z. N. Chen, and X. Qing, "Substrate integrated metamaterial-based leaky-wave antenna with improved boresight radiation bandwidth,” IEEE Trans. Antennas Propag., vol. 61, no. 7, pp. 3451-3457, 2013.

[13] Y. Mohtashami and J. Rashed-Mohassel, “A butterfly substrate integrated waveguide leaky-wave antenna,” IEEE Trans. Antennas Propag., vol. 62, no. 6, pp. 3384-3388, 2014.

[14] J. Liu, D. R. Jackson, and Y. Long, "Substrate integrated waveguide (SIW) leaky-wave antenna with transverse slots,” IEEE Trans. Antennas Propag., vol. 60, no. 1, pp. 20-29, 2012.

[15] Y. Geng et al., "High-Efficiency Leaky-Wave Antenna Array With Sidelobe Suppression and Multibeam Generation,” vol. 16, pp. 2787-2790, 2017.

[16] M. Archbold, E. J. Rothwell, L. C. Kempel, and S. W. Schneider, "Beam steering of a half-width microstrip leakywave antenna using edge loading,” IEEE Antennas Wirel. Propag. Lett., vol. 9, pp. 203-206, 2010.

[17] N. Nguyen-Trong, L. Hall, and C. Fumeaux, "Transmission-Line Model of Nonuniform Leaky-Wave Antennas," IEEE Trans. Antennas Propag., vol. 64, no. 3, pp. 883-893, 2016.

[18] W. Fuscaldo, D. R. Jackson, and A. Galli, "Beamwidth Properties of Endfire 1-D Leaky-Wave Antennas,” vol. 65, no. 11, pp. 281-282, 2017.

[19] G. Augustin, S. V. Shynu, C. K. Aanandan, P. Mohanan, and K. Vasudevan, “A novel electronically scannable logperiodic leaky-wave antenna,” Microw. Opt. Technol. Lett., vol. 45, no. 2, pp. 163-165, 2005.

[20] D. K. Karmokar, K. P. Esselle, and S. G. Hay, "Fixed-Frequency Beam Steering of Microstrip Leaky-Wave Antennas Using Binary Switches,” IEEE Trans. Antennas Propag., vol. 64, no. 6, pp. 2146-2154, 2016.

[21] R. Guzmán-Quirós, J. L. Gómez-Tornero, A. R. Weily, and Y. J. Guo, "Electronically steerable 1-d fabry-perot leaky-wave antenna employing a tunable high impedance surface,” IEEE Trans. Antennas Propag., vol. 60, no. 11, pp. 5046-5055, 2012.

[22] R. O. Ouedraogo, E. J. Rothwell, and B. J. Greetis, “A reconfigurable microstrip leaky-wave antenna with a broadly steerable beam,” IEEE Trans. Antennas Propag., vol. 59, no. 8, pp. 3080-3083, 2011.

[23] S. Lim, C. Caloz, and T. Itoh, "Electronically scanned composite right/left handed microstrip leaky-wave antenna," IEEE Microw. Wirel. Components Lett., vol. 14, no. 6, pp. 277-279, 2004.

[24] S. Doucha, M. Abri, H. A. Badaoui, and B. Fellah, "A Leaky Wave Antenna Design Based on Half-mode Substrate Integrated Waveguide Technology for X Band Applications,” Int. J. Electr. Comput. Eng., vol. 7, no. 6, p. 3467, 2017.

[25] J. Liu and Y. Long, “Analysis of a microstrip leaky-wave antenna loaded with shorted stubs,” IEEE Antennas Wirel. Propag. Lett., vol. 7, pp. 501-504, 2008.

[26] D. K. Karmokar, Y. J. Guo, P. Qin, K. P. Esselle, T. S. Bird, and L. Fellow, "Forward and Backward BeamScanning Tri-Band Leaky-Wave Antenna,” vol. 16, pp. 1891-1894, 2017.

[27] Y. Geng, J. Wang, Y. Li, Z. Li, M. Chen, and Z. Zhang, "Leaky-wave antenna array with a power-recycling feeding network for radiation efficiency improvement,” IEEE Trans. Antennas Propag., vol. 65, no. 5, pp. 2689-2694, 2017.

[28] D. M. Pozar, Microwave Engineering, Fourth Edi. JohnWiley \&Sons, Inc., 2012.

[29] Z. Zakaria, W. Y. Sam, M. Z. A. A. Aziz, A. A. M. Isa, and F. M. Johar, "Design of integrated rectangular SIW filter and microstrip patch antenna,” 2012 IEEE Asia-Pacific Conf. Appl. Electromagn. APACE 2012 - Proc., vol. 5, no. Apace, pp. 137-141, 2012.

[30] D. K. Karmokar, K. P. Esselle, and T. S. Bird, "Wideband Microstrip Leaky-Wave Antennas with Two Symmetrical Side Beams for Simultaneous Dual-Beam Scanning,” IEEE Trans. Antennas Propag., vol. 64, no. 4, pp. 1262-1269, 2016. 
[31] Z. Ma, L. Jiang, S. Gupta, and W. Sha, "Dispersion Characteristics Analysis of One Dimensional Multiple Periodic Structures and Their Applications to Antennas,” IEEE Trans. Antennas Propag., vol. 63, no. 1, pp. 113-121, 2015.

[32] O. El Maleky, F. Ben Abdelouahab, M. Essaaidi, and N. Abdelfatah, "Miniature design of T-Shaped frequency Reconfigurable antenna for S-Band Application using Switching Technique,” Int. J. Electr. Comput. Eng., vol. 7, no. 5, p. 2426, 2017.

[33] F. M. Monavar, S. Shamsinejad, R. Mirzavand, J. Melzer, and P. Mousavi, "Beam-Steering SIW Leaky-Wave Subarray with Flat-Topped Footprint for 5G Applications,” IEEE Trans. Antennas Propag., vol. 65, no. 3, pp. 1108 1120, 2017.

[34] A. Ennajih, J. Zbitou, M. Latrach, A. Errkik, and R. Mandry, "A new dual band printed metamaterial antenna for RFID reader applications,” Int. J. Electr. Comput. Eng., vol. 7, no. 6, pp. 3507-3514, 2017. 